\title{
Sharing Economy and Its Application in the Field of Transportation
}

\author{
Yudian Sui \\ School of Automobile, Chang'an University, Xi'an 710064, China. \\ effysui@163.com
}

Keywords: Sharing Economy, Collaborative Consumption, Transportation.

\begin{abstract}
To break restrictions against time, space and information, a new economic mode, the sharing economy, is in a booming state. This paper provides the definition and the origins of sharing economy and explains the development conditions in terms of economy, technology, policy and society respectively. Through the analysis of the property of sharing economy, this essay further elaborates the flourishing development of sharing economy in transportation field, which elicits the discussion about the current application of the sharing transportation. Furthermore, this essay predicts the possibility of its developments and tendency in various areas.
\end{abstract}

\section{Introduction}

\subsection{Definition.}

Sharing economy is an umbrella term with a range of meanings, often used to describe economic and social activity involving online transactions. Originally growing out of the open-source community to refer to the peer-to-peer-based activity of obtaining, giving, or sharing the access to goods and services [1], coordinated via community-based online services. Sharing economy can be seen as the effective way to alleviate social ills and environmental problems including overconsumption, air pollution, and poverty by cutting down the cost of economic coordination and so on. Also known as collaborative consumption or peer economy, a common academic definition of sharing economy refers to a hybrid market model (in between owning and gift giving) of peer-to-peer exchange. Such transactions are often facilitated via community-based online services $[1,2]$.

The phenomenon of sharing economy is a kind of economic arrangements, where participants mutualize access to products or services, rather than having individual ownership [1].

\subsection{Origins.}

As new economic structures and types emerged under the impact of the Great Recession, with the technical developments boosting rapidly and the global population growing sharply, the concept of "sharing economy" came up in the early 2000s.Professor Lawrence Lessig, is the first one to apply this concept in practice in 2008 [3, 4].

However, the advent of sharing economy certainly have appeared much before the year 2008. The Harvard law professor, Yochai Benkler, who is earliest the supporter and pioneer to use open source software supposed that the idea 'commons-based peer production' raised by him could solve the problem that the shared resources in need for the quality of life were consumed via internet technologies in 2002[5].

"Collaborative Consumption" was coined by Marcus Felson and Joe L. Spaeth in their paper "Community Structure and Collaborative Consumption: A routine activity approach" published in 1978 in the American Behavioral Scientist [6].

The concept has been supported by Rachel Botsman and Roo Rogers in their 2010 book What's Mine Is Yours: The Rise of Collaborative Consumption [7].

In 2011, Collaborative Consumption was named one of TIME Magazine's 10 ideas that will change the world [8]. 


\section{The Development Conditions of Sharing Economy}

\subsection{Technological developments.}

The rapid development of Internet is the core of the sharing economy, especially the new method of online payment such as Alipay playing a key role. People tend to prefer renting and sharing to finish the purchase. Extensive coverage of the network also spreads this philosophy to all classes and groups.

The contact of the consumption of sharing economy through the Internet has led to a trend which eliminated the intermediaries between sellers and buyers and the concentration between them on online platforms.

\subsection{Economic developments.}

The emergence and boom of sharing economy is tightly associated with the Great Recession, which is an economic downfall[7].

Oil crisis in 1970s and the weakening of the American leading economy, companies tend to reorganization, reengineering and downsizing to pay attention to the core technology in order to increase international competition. With the Internet crisis in 2000 and the subprime crisis in 2008, a stronger economic recession was faced at that time [9]. Large amounts of unemployment, deindustrialization as well as business depression declined family incomes and consuming ability.

\subsection{Political developments.}

The crumbling of the markets in developed economies and the increasingly fierce international market competitions, enterprises had intentions to restructure and realize industry optimizing and upgrading, with the aim of accelerating independent innovation and further strengthening the competitive advantages of the economy [10].

Under this condition, the society and the governments urged the act of sharing consumption, encouraging citizen take responsibilities with companies and the government collaboratively, for the purpose of regulating the balance and allocation of resources [11].

\subsection{Societal developments.}

From one aspect, sharing economy models is kind of all the humans' instincts such as collaboration, sharing, owning things and giving things. That is to say, the people in the society all have such habits and inertia to share, which provides a prerequisite of the emergence of sharing economy born in the Internet age. From another aspect, consumers always consider consumption as one of the most important part in their daily life. Therefore, sharing economy and collaborative consumption become prevalent in our society.

\section{The Transportation Sharing Economy}

Multi-Mode to Travel Choice and the Mixed Traffic make people's range of activities greatly expanded and extended. Existing traffic mode increases the efficiency of People's work, promotes the progress and social developments. However with the explosive growth of Internet information, the existing traffic mode have been hardly enough to meet the growing individual and diversity of travel requirements. People tend to choose the easier, cheaper and more efficient way to travel. Macrocosmically, general transportation have not been the rational allocation of traffic resources and the proper solution to problems.

Facing those opportunities and challenges, the general transportation have to make the change. Sharing economy can been as a great way to promote the traditional transportation.

Private and public transportation, such as buses, locomotives, ferries, and commercial airlines, all of them limit many aspects when consumers use the vehicles. In such an environment, many car- and bicycle-rental companies emerged. They allow consumers to use the vehicles with no limit in a sense. What differentiates between the new sharing-economy transportation from these existing ones is that the former mixed the developed information technology and its traditional advantage to satisfy the different and individual needs of each person's.

For example, let us assume that a large group of college students who live on campus. Each one of them has some need for a car. But they don't desire to owner a car only cared about if the car can 
be used flexibly. So the students maybe can share a single car, with several of them using it at different points during a day.

However, such a sharing transportation requires a lot of coordination. Who drives the car? How does other users informed when the car is in use at a particular time? Who pays for gas, maintenance, and insurance? In theory, all of these could all be resolved by appropriate contracting, but in practice, these logistical problems hinder such a sharing mode to become very common. New information technology, especially the powerful, widespread and so many advantages of the Internet makes the development of sharing economy more and more rapid and prominent.

The foundation of many car-sharing companies is a reliable, powerful and flexible network and importantly a smartphone app is essential to solve these interaction and coordination issues. These networks and apps enable users to get the information about the location of the cars and whether the cars is available or not.

A second form of car sharing uses the similar information technology. But these companies do not owner a real car at all, they just facilitate a transaction between vehicle owners and people who would like to use those vehicles. One version of this model, exemplified by Uber, the owner of the vehicle picks up a user and send him to the destination, much like the conventional taxi service. Another version of this model is that the vehicle owners rent their cars to users, much like a conventional carrental agency.

Compared with the car-sharing models, the development of bicycle-sharing is more rapid and more unexpected .The support and promotion of technological innovation especially the new method of payment such as Alipay and Wechat payment make the bicycle-sharing programs become the focus of the development. In China, Mobike started operating in Shanghai in April 22, 2016. In less than a year of time it has been rapidly expanding into 36 cities at home and abroad. At present, Mobike operates more than one million bicycles, the number of users more than 10 million, and the cumulative times of riding more than 500 million. Most bicycles equipped with GPS devices, making them easy to follow up and use. Now you could be shared a bicycle, as long as you have a smart phone which can pay online.

It turns out that transportation sharing economy makes traffic travel more smooth and efficient. Not matter how future holds, transportation sharing economy has already experienced tremendous growth and attracted considerable investment capital and talent.

\section{Conclusion}

Looking back to the development history of the sharing economy, people who attach great importance to the sharing economy are on the increase. As we witness the boom of this newborn economic mode, they still have all kinds of problems to face. For instance, abusing financial subsidies, incomplete supervision system and the conflict between sharing cars and traditional taxis tend to appear in term of the sharing transportation. Lack of theoretic surveys and legal restraints does exist, but both of them cannot deny the significance of the emergency of the sharing economy.

In the modern society sharing economy came up due to the prevalence of consumerism, benefitting from the development of modern information technology and the effective combination of those technique and the market economy. Therefore, it will become more significant mode of economic development in the future. As long as using the right technology, under the right conditions, with appropriate benefits, we will share everything. Patients can share medical records to improve their own treatment. Readers can share reading experiences to diverge their own thoughts. Entrepreneurs can share their state of the economy to create more wealth for society.

In the future, our lives have been networked, and the amount of information that I shared and others shared with me is increasing. The steady progress with sustained updates and supplemented by debugging makes life optimized. Sharing is almost never interrupted, even silence is shared. 


\section{References}

[1]. Hamari, J., Sjöklint, M., \& Ukkonen, A. (2016). The sharing economy: why people participate in collaborative consumption. Journal of the Association for Information Science and Technology, 67(9), 2047-2059.

[2]. Leslie Hook (22 June 2016). "Review - 'The Sharing Economy', by Arun Sundararajan" (registration required). Financial Times. Retrieved 2016-07-15.

[3]. Alex Stephany (2015). The Business of Sharing: Making it in the New Sharing Economy. Palgrave Macmillan UK.

[4]. "Homestay is the origin of Sharing Economy". PR Newswire. 2014-03-11. Retrieved 2016-0715.

[5]. Benkler, Yochai (2002). "Coase's Penguin, or, Linux and The Nature of the Firm". The Yale Law Journal. 112. Retrieved 13 June 2013.

[6]. Felson, Marcus and Joe L. Spaeth (1978), "Community Structure and Collaborative Consumption: A routine activity approach," American Behavioral Scientist, 21 (March-April), 614-24.

[7]. Botsman, R., \& Rogers, R. (2010). What's mine is yours: the rise of collaborative consumption. Harper Collins.

[8]. (2011). The 10 ideas that will change the world--for the better. Time International.

[9]. Tridico, P. (2012). Financial crisis and global imbalances: its labour market origins and the aftermath. Cambridge Journal of Economics, 36(1), 17-42.

[10]. [10]. Brunsson, N. (1994). Politicization and 'company-ization'-on institutional affiliation and confusion in the organizational world. Management Accounting Research, 5(3-4), 323-335.

[11]. [11]. Habisch, A. (2011). Politicization of Companies? Empirical Evidence on Corporate Citizenship Activities in Europe. Corporate Citizenship and New Governance. Springer Netherlands. 